\title{
Cooling tower plume - model and experiment
}

\author{
Jan Cizek $^{1}$, Jiri Gemperle ${ }^{1}$, Miroslav Strob $^{1}$ and Jiri Nozicka ${ }^{1}$ \\ ${ }^{1} \mathrm{CTU}$ in Prague, Faculty of Mechanical Engineering, Technicka 4, 16607 Prague, Czech Republic
}

\begin{abstract}
The paper discusses the description of the simple model of the, so-called, steam plume, which in many cases forms during the operation of the evaporative cooling systems of the power plants, or large technological units. The model is based on semi-empirical equations that describe the behaviour of a mixture of two gases in case of the free jet stream. In the conclusion of the paper, a simple experiment is presented through which the results of the designed model shall be validated in the subsequent period.
\end{abstract}

\section{Introduction}

The cooling towers are used in many industrial plants as a system for efficient and reliable liquidation of lowpotential waste heat. Their history dates back far into the past and first mention of the basic principles of evaporative cooling (respectively, the fact that it is possible to achieve a certain level of cooling by evaporation) can be found already more than 2,500 years BC. Application of this type of cooling in industrial practice started in the second half of the 19th century. At present, cooling towers working on the evaporative cooling principle are relatively standard technological units, which can be supplied on contractor basis without any major problems in a practically arbitrary range of required outputs (the smallest fan cooling towers are currently made from app. dimensions of $0.5 \times 0.5 \mathrm{~m}$ ).

Cooling tower issues are discussed in many professional publications. The basic publications may be considered as the books [1] and [2], and from the ranks of professional articles, these are, for instance, [3], [4], [5], or [6]. This contribution is then from the viewpoint of the field of evaporative cooling tied to the relatively narrow issue of the creation of the steam plume. Few global professional publications exist about their characteristics and behaviour, however, worth mentioning are publications [7] and [8] which although a bit old, nevertheless, present an idea in the given issue.

\section{Velocity field}

The mathematical model used to get the basic idea of the behaviour of the steam plume is based on the solution presented in the paper [9]. It is a semi-empirical model of the free stream jet flow from the circular or rectangular nozzle. Schematically, the geometrical characteristics of this flow are given in Fig. 1, where the detail in the vicinity of its outlet is shown on the right side. The model in itself practically respects on the retention of the overall momentum of the flow without considering any other influences. Although it is a relatively trivial model, its resultant values (e.g. in the form of the shape of the velocity profile, or progress of the decline of the mean velocity on the flow axis) do not differ much from the more sophisticated models.
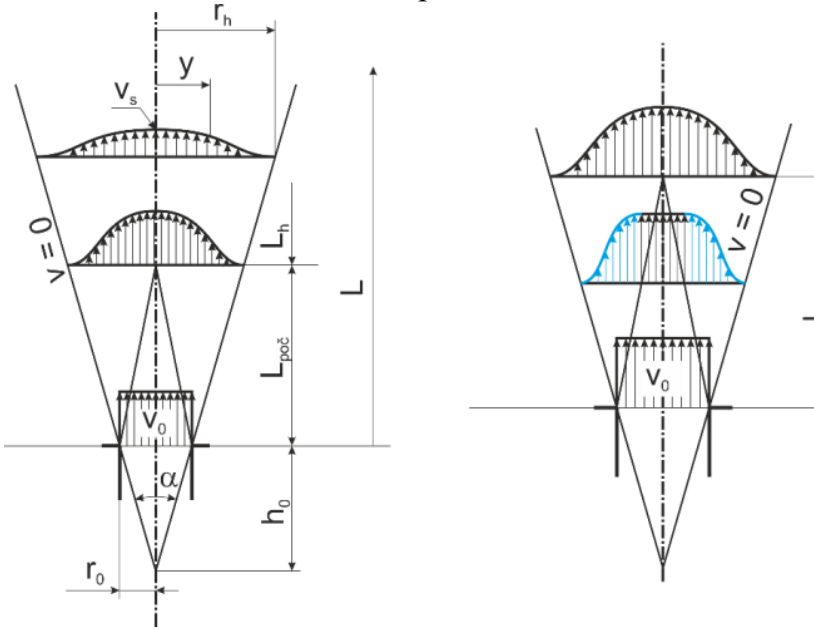

Fig. 1: Geometrical characteristics of the considered model

The velocity field is subsequently described in the system of linear algebraic equations 1 to 5

$$
\begin{gathered}
L_{p o \check{c}}=\left(0.67 \cdot r_{0}\right) / a \\
L_{p o \check{c}}=\left(0.29 \cdot r_{0}\right) / a \\
r_{h}=3.3 \cdot r_{0} \cdot v_{0} / v_{s} \\
v_{s}=\left(0.96 \cdot v_{0}\right) /\left[(a \cdot L) / r_{0}+0.29\right] \\
v=v_{s} \cdot\left[1-\left(y / r_{h}\right)^{(3 / 2)}\right]^{2}
\end{gathered}
$$

Symbol $\boldsymbol{a}$ shown in equations 1 to 5 is the, so-called, coefficient of the structure of the flow and an adequately large Reynolds Number $(\operatorname{Re}>2.104)$ it is not dependent on the Reynolds Number. In the publication [9], it is recommended for the circular nozzle section to use the value $\boldsymbol{a}=\mathbf{0 . 0 7} \div \mathbf{0 . 0 8}$. The values given for the velocity at an arbitrary flow point (5), respectively, for the 
velocity in the flow axis (4), it is then comprehensively valid only for the area where $\boldsymbol{L} \geq \boldsymbol{L}_{\text {poc }}$.

From the given equations (1) and (2), it is also good to notice the facts that the values $\boldsymbol{L}_{\boldsymbol{p} o c}$ and $\boldsymbol{h}_{\boldsymbol{o}}$ are dependent only on the parameters $\boldsymbol{r} \boldsymbol{o}$ and $\boldsymbol{a}$. Due to the potential recommended distribution of the values of parameter $\boldsymbol{a}$ it is possible to state that the size of the area, which is affected by the exit flow depends only on its diameter.

The advantage of the solution in [9] is, among other things, that it is possible to expand it further with the velocity of the ambient air in a case where the spreading of the steam plume is influenced by cross wind. In this situation, it is therein recommended for calculation of the centre line of the derived velocity profile to use the equation (6) in the shape

$$
\begin{aligned}
a \cdot y /\left(2 \cdot r_{0}\right)= & 195 \cdot\left(\rho_{o k} \cdot v_{o k}^{2} /\left(\rho_{0} \cdot v_{0}^{2}\right)\right)^{1,3} . \\
& \left(a \cdot x /\left(2 \cdot r_{0}\right)\right)^{3}+a \cdot x /\left(2 \cdot r_{0}\right) \cdot \operatorname{cotg} \alpha .
\end{aligned}
$$

The given equation was approximated from the experimental data and its area of validity is therefore very limited, specifically up to an ambient air velocity of about 0.3 -fold the velocity of the main flow. In real cases, a horse-shoe shaped vortex is also created after the outlet from the cooling tower and the whole issue is therefore generally more complicated. For the conclusions derived here, however, this statement suffices. In order to allow, also in this case, for design of the shape of the velocity profile at the individual points in the evaluated area, the velocity profiles obtained in the equation (5) are transformed into the curvilinear coordinate system defined by equation (6) (Fig. 3).

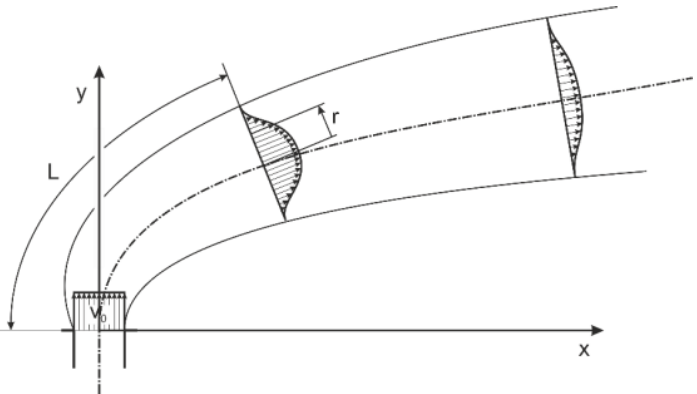

Fig. 2: Curvilinear coordinate syst. defined in the equation (6)

The results of the given model are schematically shown in Fig. 3.

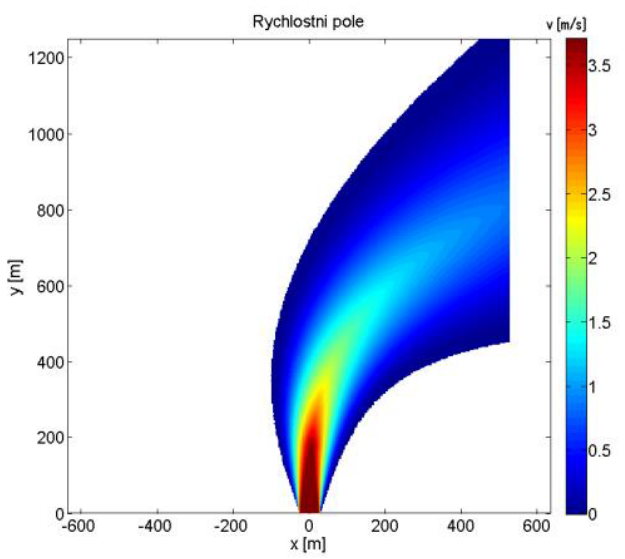

Fig. 3: Evaluated velocity fields

\section{Concentration field}

For the concentration field of two gases of same density and known velocity field shown in the preceding chapter, [9] recommends use of the relationships on the analogy between the dimensionless velocity and concentration field in the form:

$$
c_{i, s}=0.96 /\left[(a \cdot L) / r_{0}+0.26\right]
$$

If the velocity of the ambient air shall be zero and the individual specific humidities of the concerned media shall be equal to $\mathrm{x}_{1}$ for the ambient air, respectively, $\mathrm{x}_{2}$ for the effluent air from the cooling tower, we can, due to the fact that equation (7) is written for molar concentration, directly derive the equation for the specific air humidity in the area influenced by the flow stream that is defined by the equations (1) to (6). The resultant specific humidity shall be given by the equation

$$
x=x_{1}+\left(x_{s}-x_{1}\right) \cdot\left(v / v_{s}\right)^{0.5}
$$

where we determine the value $\boldsymbol{x}_{\boldsymbol{s}}$ from the equation

$$
x_{s}=0.96 \cdot\left(x_{2}-x_{1}\right) /\left[(a \cdot L) / r_{0}+0.26\right]+x_{1}
$$

The specific humidity fields calculated on the basis of the velocity field and equations (8) and (9) is given in the graph in Fig. 4 for the case with side wide wind.

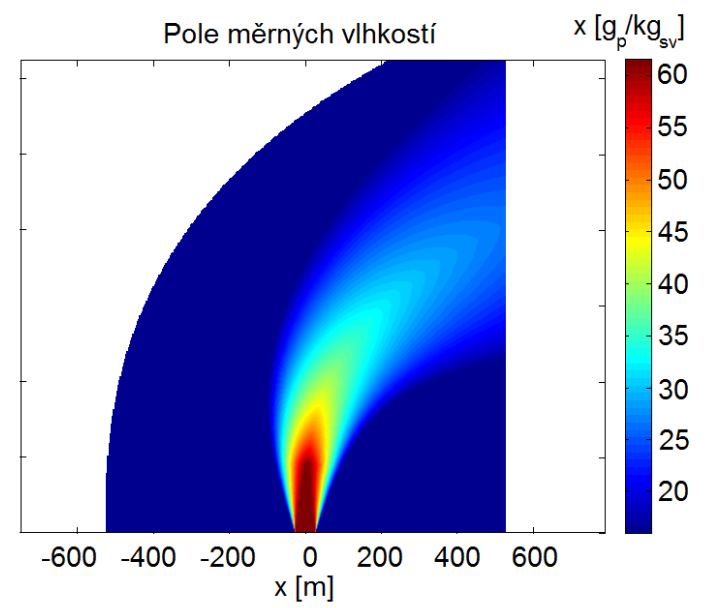

Fig. 4: Specific humidity field

The acquired velocity and in relation to it, also the humidity field in the area above the cooling tower makes it possible in the following paragraphs to make an elementary determination of the assumed shape of the plume, which is directly tied to the specific humidity values. It is clear that if the specific humidity at a given point is higher than the one that would correspond to the supersaturated vapour pressure at a given pressure and temperature, water vapour condenses in the space above the cooling tower in the form of droplets and thus creates a visible plume.

\section{Plume}

In order to be able to use the specific humidity field to determine the condensed water volume, it is first 
necessary to know either the temperature or enthalpy at the given point. In publication [9], practically the same equation is given for the temperature as in the equation (9) for concentration. Even here, it is however necessary to realise that unlike the concentrations, which are expressed as molar and equation (9), it applies for them that the temperature variable cannot be valid. This is due to the fact that in the entire process, a change occurs in state of matter and part of the heat energy, which is necessary for such change, is saturated just by the local drop in temperature. Due to the above-stated, for description of the local humid air condition, it is thus necessary to determine the enthalpy value.

Just line the corresponding specific humidity, we can also determine the enthalpy as such from the Mollier $\mathrm{h}_{1+\mathrm{x}} \mathrm{x}$ diagram using the lever rule; clearly, the analogous equations in equations (8) and (9) must apply to it. By using enthalpy in place of the specific humidity, we thus get

$$
h=h_{1}+\left(h_{s}-h_{1}\right) \cdot\left(v / v_{s}\right)^{0.5}
$$

where we determine the value $\boldsymbol{h}_{\boldsymbol{s}}$ from the equation

$$
h_{s}=0.96 \cdot\left(h_{2}-h_{1}\right) /\left[(a \cdot L) / r_{0}+0.26\right]+h_{1}
$$

If it is now possible on the basis of equations (6) to (9) in the monitored space for all its points to determine the image in the Mollier diagram $\mathrm{h}_{1+\mathrm{x}}-\mathrm{x}$, it is possible to finally calculate the local temperature value, but simultaneously also the specific humidity corresponding to the satration curve. This concerns points with the same specific enthalpy and different specific humidity. In areas where the difference of the two stated humidity values is positive, it is thus possible to assume the presence of the steam plume (see Fig. 5).

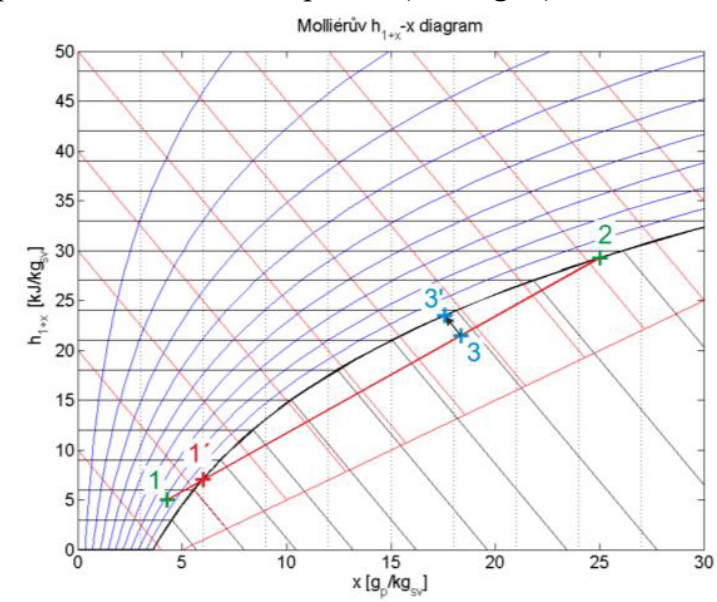

Fig. 5: The plume shall appear at the given point if such point shall lie on the connecting lime of points 1 'and 2.

The results of the aforementioned procedure are given in Fig. 6 for the normally achieved values of the individual variables.

Here, it is necessary to mention the fact that this case concerns a maximalist estimate. For evaluation of the shape and size of the plume, its visibility is relatively important. It is always the result of a combination of a number microscopic droplets in a unit volume, their average size and light conditions. It generally applies that the plume shall be visible in case of an adequately large number of particles of adequate size in a unit volume. In this context, it is necessary to realise that it is not true to state that condensation occurs for the points of the connecting line 1 'and 2 . In fact, it is true that between points 1 'and 2 the air is in state of supersaturation even in a situation in which the water evaporates from the surface of the droplets present. For this reason, the overall volume of plume evaluated from Fig. 6 shall be the maximum possible volume.

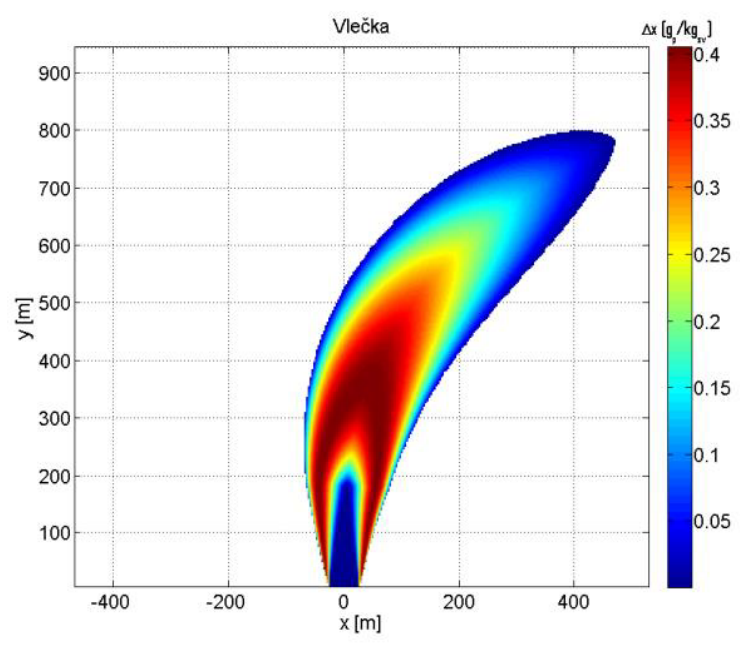

Fig. 6: Plume presence area.

Due to the above-stated, the given plume model can be supplemented, for instance, with the visibility condition stated above and analysed further. It is then possible to deduce many interesting facts, for instance, the fact that the overall volume, which the plume covers in the space depends only on the output diameter of the cooling tower and the states of the two mixed air masses (effluent air from the cooling tower and ambient air). In detail, the entire deduction is given, for instance, in [10]; for this reason, we limit ourselves in this case only to statement of the resultant relationship (10)

$$
V_{\text {plume }}=C \cdot\left[\left(x_{2}-x_{1}\right) /\left(x_{1}{ }^{\prime}-x_{1}\right)\right]^{3} \cdot D^{3}
$$

It is just the constant $C$ in the given equation (10) that is influenced by the above-stated facts relating to the visibility of the plume. It is possible to demonstrate that in an idealised case, its value should be equal to $C=\mathbf{2 . 5}$.

\section{Verification experiment}

In order to be able to assess whether and eventually to what extent the results of the above-stated model correspond to reality, a simple experiment was designed. Currently, relevant experimental data are not available in professional literature. The only available publication, which discusses the given issue (8) refers to the results obtained from experiments in the USA in the seventies of the last century. The second possibility would thus be to compare the results to some other computational procedure, e.g. (11); however, a risk exists here consisting in the unknown precision of such a model. 
The experiment is based on use of simple visualisation techniques together with the ambient conditions data (temperature, pressure, humidity and wind direction and velocity) and the data on the effluent air flow from the cooling tower. These values cannot be measured directly in a simple way. For this reason, an experiment is currently being designed in which the parameters describing the thermodynamics of the condition of the cooling tower shall be monitored (flow rate and input and output temperature of the water), from which by means of known tower characteristics, the condition of the air at its outlet shall be calculated additionally.

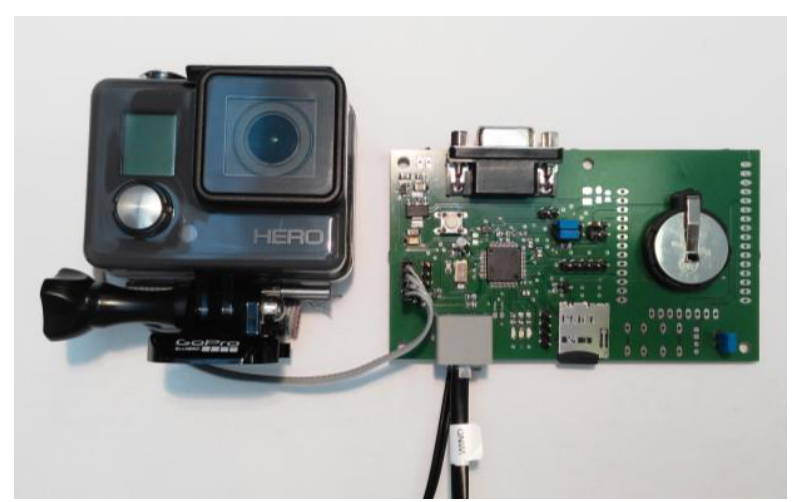

Fig. 7: The device for experimental determination of the size of the plume in varying atmospheric conditions

The device itself (Fig. 7) is based on a microprocessor with ARM core by ST Microelectronics and is used to record the wind speed and direction data from the cup anemometer (Fig. 8); it is further possible to take a photograph or make a short video recording using the external camera. After installation of an external sensor, we additionally get atmospheric press, temperature and humidity data.

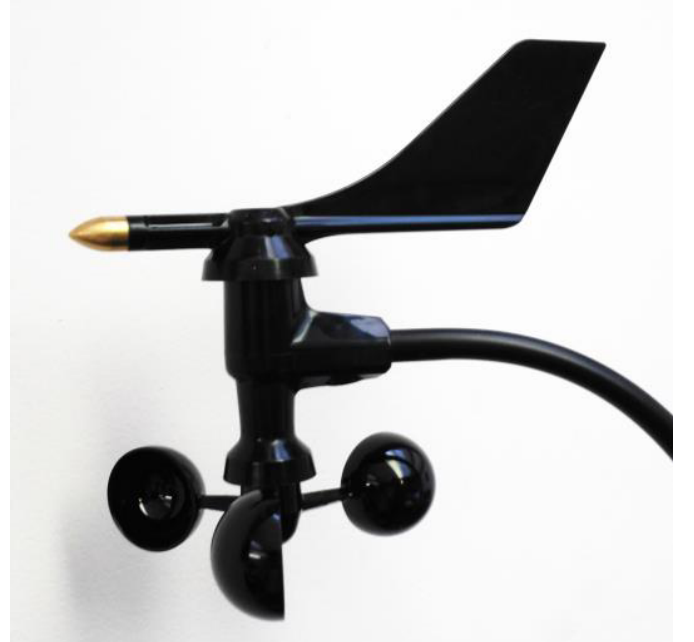

Fig. 8: Cup anemometer

The device was designed for easy operation and reliability - the camera is selected as a generally available product for amateur photography with a high resolution, the camera power supply is solved by means of an in-built Li-Po accumulator and the data is stored on a standard microSD card. A similar solution is also applied to the design device that is powered by a single- cell Li-Po accumulator; the record is stored on a microSD card with FAT16 file system that can be processed easily on a PC. A record is made within the required time intervals. To save power, the processor is kept in standby mode during idle time and is activated only upon measurement query. The microprocessor contains a real-time circuit with external battery back-up that keeps the clock running even when the accumulator is disconnected. The time can be set on the real time circuit via standard serial line RS-232 using a set AT commands; in future, it will be possible to equip the device with a DCF-77 precision time receiver for automatic time setting and adjustment.

\section{References}

1. D. G. Kröger: Air-cooled heat exchangers and cooling towers: thermal-flow performance evaluation and design, Volume I, Penn Well Corporation, Oklahoma (2004)

2. D. G. Kröger: Air-cooled heat exchanger and cooling towers: thermal-flow performance evaluation and design, Volume II, Penn Well Corporation, Oklahoma (2004)

3. F. Merkel: Verdunstungskühlung, VDI Zeitchrift Deustscher Ingenieure, Vol. 70, pp. 123-128, (1925)

4. J. C. Kloppers, D. G. Kröger: Cooling tower performnnce: A critical evaluation of the Merkel assumptions, International Journal of Thermal Science, Vol. 44, (2005)

5. Hyhlík, T., Quasi One-Dimensional Model of Natural Draft Wet-Cooling Tower Flow, Heat and Mass Transfer (2015) EPJ Web of Conferences, 92, art. no. 02027 ,

6. Hyhlík, T. Concept of CFD model of natural draft wet-cooling tower flow (2014) EPJ Web of Conferences, 67, art. no. 02044,

7. W. E. Dunn, L. Coke, A. J. Policastro: Coolingtower-plume prediction code, Engineering and Environmental Science (1987), Illinois, US

8. A. Kouchi, R. Ohba, K. Okabayashi, T. Nonaka: Prediction technique for visible plume from cooling tower, Mitsubishi Heavy Industries Ltd., Technical Review, Vol. 36, No. 3, (1999)

9. M. Rédr, M. Příhoda: Základy tepelné techniky, SNTL, Praha (1991)

10. Čížek, J. - Nožička, J.: Cooling tower plume, 35. Stretnutie kateder mechaniky tekutín a termomechaniky. AIP Conference Proceedings, (to be published)

11. Hyhlík, T.: Mathematical model of unsaturated and supersaturated moist air flow based on two pasive scalar transport equation, 35. Stretnutie kateder mechaniky tekutín a termomechaniky . AIP Conference Proceedings, (to be published) 